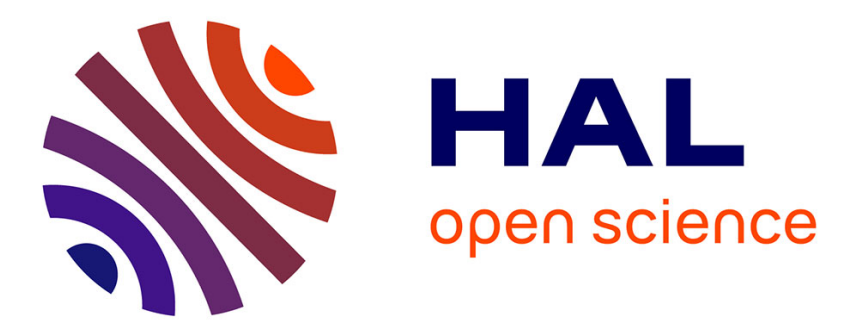

\title{
Controlled drive-in and precipitation of hydrogen during plasma hydrogenation of silicon using a thin compressively strained SiGe layer
}

\author{
F. Okba, Nikolay Cherkashin, Z. Di, M. Nastasi, F. Rossi, A. Merabet, Alain
}

Claverie

\section{To cite this version:}

F. Okba, Nikolay Cherkashin, Z. Di, M. Nastasi, F. Rossi, et al.. Controlled drive-in and precipitation of hydrogen during plasma hydrogenation of silicon using a thin compressively strained SiGe layer. Applied Physics Letters, 2010, 97 (3), pp.31917-31917. 10.1063/1.3467455 . hal-01736050

\section{HAL Id: hal-01736050 https://hal.science/hal-01736050}

Submitted on 23 Mar 2018

HAL is a multi-disciplinary open access archive for the deposit and dissemination of scientific research documents, whether they are published or not. The documents may come from teaching and research institutions in France or abroad, or from public or private research centers.
L'archive ouverte pluridisciplinaire HAL, est destinée au dépôt et à la diffusion de documents scientifiques de niveau recherche, publiés ou non, émanant des établissements d'enseignement et de recherche français ou étrangers, des laboratoires publics ou privés. 
Controlled drive-in and precipitation of hydrogen during plasma hydrogenation of silicon using a thin compressively strained SiGe layer

F. Okba, N. Cherkashin, Z. Di, M. Nastasi, F. Rossi, A. Merabet, and A. Claverie

Citation: Appl. Phys. Lett. 97, 031917 (2010); doi: 10.1063/1.3467455

View online: https://doi.org/10.1063/1.3467455

View Table of Contents: http://aip.scitation.org/toc/apl/97/3

Published by the American Institute of Physics

Articles you may be interested in

Temperature dependencies of hydrogen-induced blistering of thin film multilayers

Journal of Applied Physics 115, 173510 (2014); 10.1063/1.4875484

Plasma hydrogenation of strained $\mathrm{Si}$ / SiGe / Si heterostructure for layer transfer without ion implantation Applied Physics Letters 87, 091902 (2005); 10.1063/1.2032602

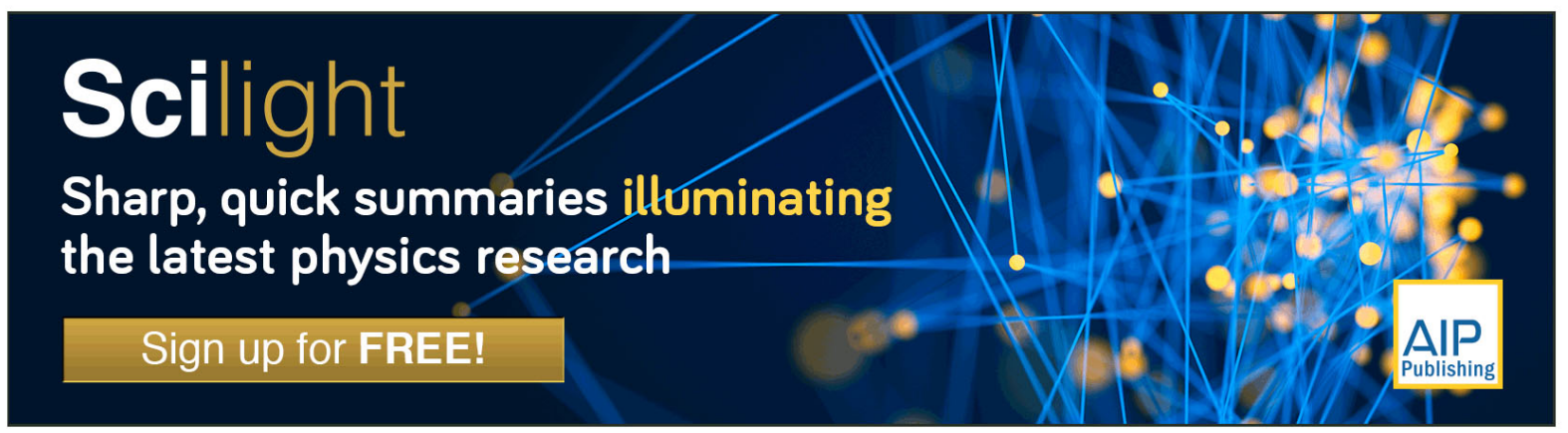




\title{
Controlled drive-in and precipitation of hydrogen during plasma hydrogenation of silicon using a thin compressively strained SiGe layer
}

\author{
F. Okba,,$^{1,2}$ N. Cherkashin, ${ }^{1, a)}$ Z. Di, ${ }^{3}$ M. Nastasi, ${ }^{3}$ F. Rossi, ${ }^{4}$ A. Merabet, ${ }^{2}$ and \\ A. Claverie ${ }^{1}$ \\ ${ }^{1}$ CEMES/CNRS and University of Toulouse, Groupe nMat, 29 rue J. Marvig, 31055 Toulouse, France \\ ${ }^{2}$ Département Optique et Mécanique de Précision, Faculté des Sciences de l'Ingénieur, \\ Université Ferhat Abbas, Sétif 19000, Algeria \\ ${ }^{3}$ Materials Physics and Applications Division, Los Alamos National Laboratory, Los Alamos, \\ New Mexico 87545, USA \\ ${ }^{4}$ Joint Research Centre, European Commission, Ispra(Va) 21020, Italy
}

(Received 26 May 2010; accepted 1 July 2010; published online 23 July 2010)

\begin{abstract}
We have quantitatively studied by transmission electron microscopy the growth kinetics of platelets formed during the continuous hydrogenation of a $\mathrm{Si}$ substrate/SiGe/Si heterostructure. We have evidenced and explained the massive transfer of hydrogen from a population of platelets initially generated in the upper Si layer by plasma hydrogenation towards a population of larger platelets located in the SiGe layer. We demonstrate that this type of process can be used not only to precisely localize the micro-cracks, then the fracture line at a given depth but also to "clean" the top layer from pre-existing defects. (C) 2010 American Institute of Physics. [doi:10.1063/1.3467455]
\end{abstract}

In the conventional ion-cut technology (SmartCut $\left.{ }^{\mathrm{TM}}\right)$, hydrogen ion implantation followed by wafer bonding and thermal annealing is used for the transfer of a Si film onto an oxidized substrate. ${ }^{1}$ This process takes advantage of the precipitation of hydrogen during annealing in the form of quasitwo dimensional defects filled with over-pressurized $\mathrm{H}_{2}$ gas. These defects exert stress in the layer and, during annealing, their thermal evolution from "platelets" of a few tens of nm in diameter to micro-cracks of a few micrometers in diameter and the possibility for them to elastically interact may give rise to the complete exfoliation of the upper layer. ${ }^{2}$

For high enough implanted fluences, the majority of platelets and subsequent micro-cracks are parallel to a (001) $\mathrm{Si}$ wafer surface and the thickness of the transferred layer can be monitored by varying the beam energy. ${ }^{1}$ However, the depth-straggling of the implanted ions results in a depthdistribution of platelets and micro-cracks which, in turn, results in a quite severe roughness and relatively high defectivity of the transferred layers. For this reason, ultrathin (few nanometer thick) layers, desirable for developing advanced silicon-on-insulator technologies, are difficult to fabricate using ion implantation and require time-consuming and costly etching steps.

Plasma hydrogenation, a low cost and flexible technique, can be used to inject hydrogen into silicon. ${ }^{3,4}$ Nevertheless, as the energy of the $\mathrm{H}$ ions impacting the surface is low and spread, the platelets are depth-distributed all over the nearsurface region. Moreover, mostly $\{111\}$ platelets not parallel to the wafer surface, the most stable defects in absence of stress, ${ }^{5}$ are formed during hydrogenation. ${ }^{3-5}$ As a consequence, plasma hydrogenation alone cannot be used to transfer layers of sufficiently high crystalline quality.

It has been previously reported that thin SiGe strained layers buried during growth in a Si substrate can be used to favor the formation of platelets parallel to the wafer surface and located on or close to the stressed layer. ${ }^{6,7}$ However, up

${ }^{a)}$ Electronic mail: nikolay.cherkashin@cemes.fr. to now, the mechanisms responsible for such behavior were not clearly understood and the crystalline quality of the upper layer was poor due to the formation of platelets and micro-cracks of undesirable orientations therein.

In this work, we identify those mechanisms and demonstrate the possibility to localize all the micro-cracks, and finally the splitting-depth of transferred layers, precisely onto a thin compressively strained SiGe layer while leaving a perfectly defect-free upper layer by using plasma hydrogenation.

For the experiments reported here, a defect-free structure containing a $5 \mathrm{~nm}$ thick compressive strained $\mathrm{Si}_{0.80} \mathrm{Ge}_{0.20}$ layer covered by a $180 \mathrm{~nm}$ thick Si layer was grown by molecular beam epitaxy on a (001) Si substrate. The wafer was cut into four pieces which were subjected to low pressure (1 mTorr) plasma hydrogenation in pure hydrogen during $0.5 \mathrm{~h}, 1 \mathrm{~h}, 1.5 \mathrm{~h}$, and $2 \mathrm{~h}$, respectively. Hydrogenation was carried out in a distributed electron cyclone resonance plasma reactor with a low frequency $(2 \mathrm{kHz})$ bias equal $-100 \mathrm{~V}^{8}$ The plasma temperature was of about $300{ }^{\circ} \mathrm{C}$. Specimens were prepared for cross-section (CS) imaging using transmission electron microscopy (TEM) along both the [110] and [010] directions by tripod polishing and low energy/current density argon ion-beam thinning until electron transparency. The platelets and micro-cracks seen edge-on contained in a given region of a sample were all detected in TEM images taken under specific out-of-Bragg and out-of-focus conditions. ${ }^{9}$ Then, the thickness of the analyzed areas was estimated by imaging the same zones under well-defined two-beam conditions. The defect populations were statistically analyzed over several images in terms of depth-distributions of their size, concentration, and volume fraction they occupy following the method developed in our previous works. $2,9,10$

Typical images from the samples subjected to hydrogenation for $0.5 \mathrm{~h}, 1 \mathrm{~h}, 1.5 \mathrm{~h}$, and $2 \mathrm{~h}$ are shown in Figs. 1(a)-1(d), respectively. As already reported in Ref. 11, a 10-20 nm thick $\mathrm{SiO}_{2}$ layer is formed on all samples during hydrogenation. For hydrogenation times up to $1.5 \mathrm{~h}$, different 


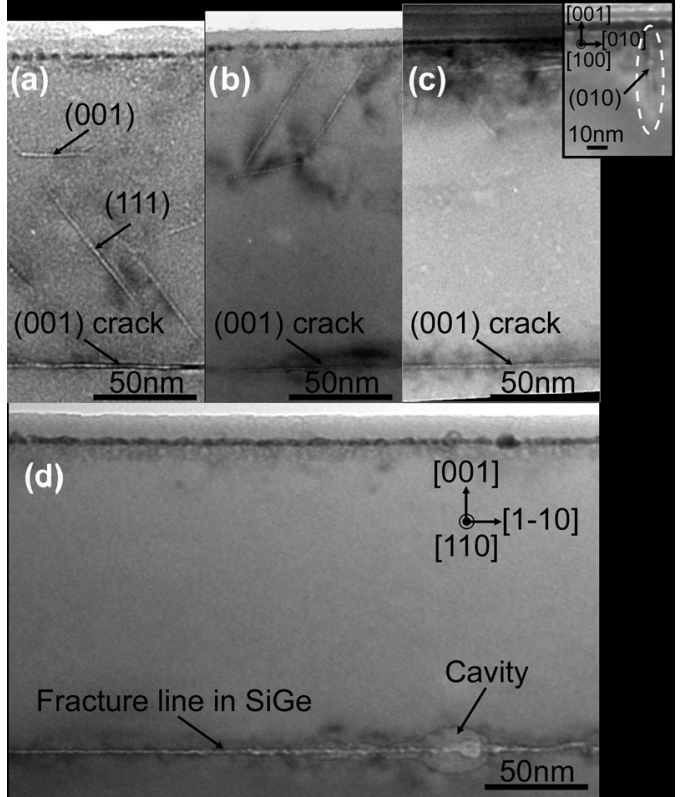

FIG. 1. Bright-field off-Bragg underfocused CS (110) images of the Si/ $\mathrm{SiGe} / \mathrm{Si}$ heterostructure subjected to plasma hydrogenation during (a) $0.5 \mathrm{~h}$, (b) $1.0 \mathrm{~h}$, (c) $1.5 \mathrm{~h}$, and (d) $2.0 \mathrm{~h}$. Inset in (c) CS (100) image of a (010) platelet.

types of platelets lying on $\{111\}$ s, (001) and, in much smaller concentrations, on (010) planes are observed in the upper $\mathrm{Si}$ layer. As the hydrogenation time increases, a defect-free layer appears and develops extending from the $\mathrm{SiGe}$ layer towards the surface. After hydrogenation for $2 \mathrm{~h}$, no defects are observed in the Si upper layer [Fig. 1(d)] except in a very narrow, a few nanometer thick, layer close to the surface. In all the samples, platelets and/or micro-cracks parallel to the (001) Si surface are observed within the SiGe layer. As the hydrogenation time increases from 0.5 to $1.5 \mathrm{~h}$, the isolated platelets located there grow in size and eventually merge to form micro-cracks. After $2 \mathrm{~h}$ of hydrogenation, these microcracks have grown in size and/or coalesced and initiate a fracture line in the SiGe layer, thus parallel to the wafer surface. Few round shaped cavities are also observed at the same depth.

Figure 2 gathered the results of the quantitative analysis of these defect populations in terms of defect density, diameter and volume fraction as functions of the depth. After hydrogenation for $0.5 \mathrm{~h}$, the concentration of platelets follows a quasilognormal profile centered at a depth of $60 \mathrm{~nm}$ below the surface with a long tail extending toward the SiGe layer [Fig. 2(a)]. As the hydrogenation time increases, this concentration profile shrinks from the long tail side, shifts toward the surface and finally its integral decreases as confirmed by the evolution of the projected superficial density shown in the inset in Fig. 2(a). Interestingly, the concentration of defects within the SiGe layer remains mostly unaffected by the hydrogenation time. In all samples, the closer to the SiGe layer the larger the platelets are [Fig. 2(b)]. The platelets located within the SiGe layer are already larger at the beginning of hydrogenation but further grow faster than elsewhere in the Si layer during hydrogenation [see inset in Fig. 2(b)]. As the hydrogenation proceeds, all the platelets grow in size but their growth rate increases when the distance to the SiGe layer decreases. Figure 2(c) shows the evolution of the volume fraction occupied by the platelets

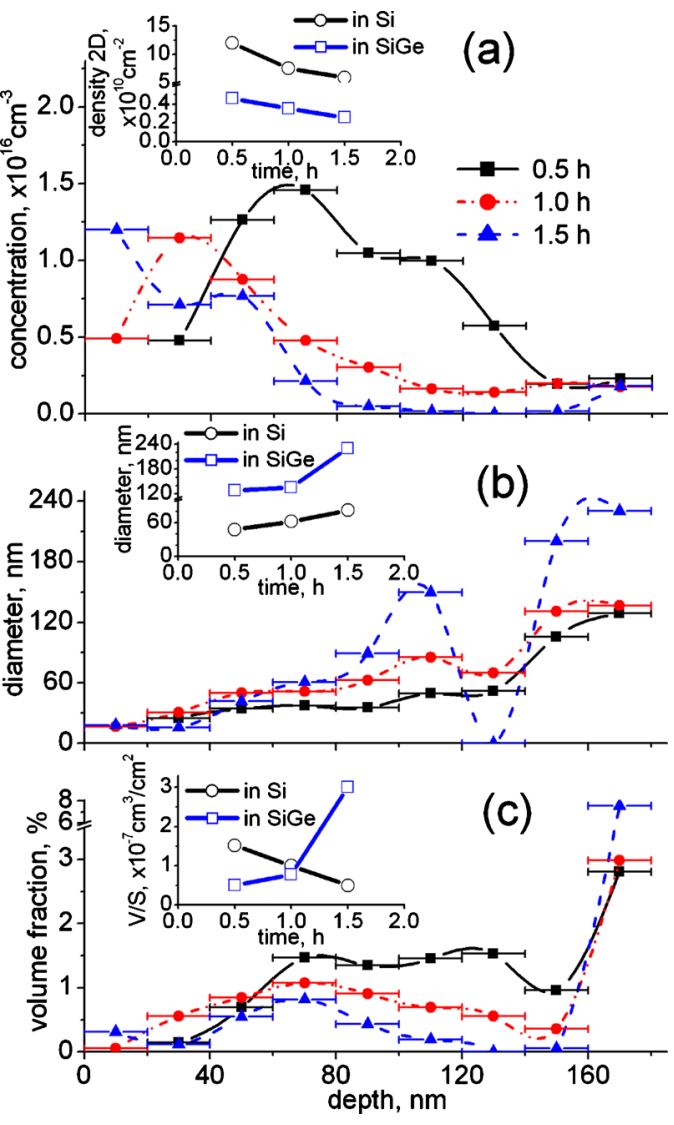

FIG. 2. (Color online) Depth-distributions of the platelet concentration (a), mean diameter (b), and occupied volume fraction (c) as functions of the hydrogenation time. Results compiled for "depth-classes" of $20 \mathrm{~nm}$ wide. The relative uncertainties in those measurements are $20 \%, 10 \%$, and $50 \%$, respectively. Insets in (a), (b), and (c) show the time-evolution of the integrals of these profiles in the upper $\mathrm{Si}$ and in the SiGe layers, i.e., platelet projected surface density, average diameter, and volume per surface fraction, respectively.

and micro-cracks obtained by combining the results shown in Figs. 2(a) and 2(b). After 0.5 h hydrogenation, the "platelet phase" mostly occupies a region located in the Si layer from a depth of 80 to $140 \mathrm{~nm}$ from the surface. Owing to their very large size there, the platelets occupy a large volume fraction of the SiGe layer. However, when the hydrogenation proceeds, the volume fraction in the Si layer decreases everywhere but faster close to the surface and to the $\mathrm{SiGe}$ layer. In the meantime, it dramatically increases in the SiGe layer. Integrating these depth distributions, we evidence in the inset of Fig. 2(c) that the volume per surface fraction, V/S, decreases linearly with time in the Si upper layer but increases exponentially in the $\mathrm{SiGe}$ layer.

In these experiments, we believe that we have evidenced the massive transfer of hydrogen from a population of platelets initially generated in the upper Si layer by plasma hydrogenation towards a dense population of larger platelets located in the SiGe layer. This phenomenon which results both in the fracture of the material at the depth of the SiGe layer but also in the "cleaning" of the Si upper layer is not only scientifically intriguing but also of paramount importance for applications. We will discuss it in the following.

During hydrogenation two phenomena take place simultaneously, the injection of very low energy $\mathrm{H}^{+}$ions and annealing. As the injected fluence increases, new platelets can be nucleated in the Si layer while those already formed can 
grow by trapping the $\mathrm{H}$ atoms and vacancies generated by the hydrogenation process. Because the "annealing time" also increases during plasma treatment, these platelets also evolve by "classical" Ostwald ripening. ${ }^{9}$ Thus, in principle, the evolution of the population of the platelets located in the upper Si layer should results in an increase in both their diameter and the volume fraction they occupy. Our experimental results show that while the mean diameter of the platelets slowly increases, their surface density decreases and the volume-per-surface fraction they occupy rapidly falls down, a set of properties characteristic of a nonconservative Ostwald ripening phenomenon taking place in presence of a sink, and not of a source. Obviously, the sink for the $\mathrm{H}$ atoms and vacancies provided both by hydrogenation and by the dissolution of these platelets are the (001) platelets observed in the SiGe layer. As the mean size of the platelets located within the SiGe layer is always much larger that the mean size of those located in the Si layer, the former grow at the expense of the later. Our result also shows that the sink efficiency of the SiGe layer is higher than the source strength provided by hydrogenation. We deduce that, during hydrogenation, there exists a strong concentration gradient of $\mathrm{H}$ atoms and vacancies decreasing from the surface (source) towards the SiGe layer. Thus, during hydrogenation, since the platelets located in the SiGe layer grow in size, the hydrogen and vacancies newly injected in the near surface region are transferred preferably toward the SiGe layer before nucleating new platelets and with a rate which increases with the hydrogenation time. The existence of this gradient and associated flux is confirmed by the observation that the closer the platelets are to the SiGe layer the longer they grow before dissolution. In addition, the gradient of $\mathrm{H}$ atoms existing in the top Si layer has been observed by secondary ion mass spectrometry previously. ${ }^{11}$ This phenomenon is irreversible and once initiated results in the complete depletion of the $\mathrm{Si}$ layer.

However, this scenario requires that, at the beginning of the plasma treatment, (001) platelets are formed in SiGe with diameters larger than those forming in the upper Si layer. As the SiGe layer is under compression, it is unlikely that $\mathrm{H}$ preferentially diffuses towards it. Alternatively, this layer is a strong sink for the vacancies created by the bombardment, as these defects help relaxing the stress in the layer ${ }^{12}$ and thus the overall elastic energy of the system. Once this layer is enriched with vacancies, it can trap $\mathrm{H}$ atoms easily forming $\mathrm{V}_{\mathrm{m}} \mathrm{H}_{\mathrm{n}}$ complexes which can precipitate or coalesce to form platelets. $^{2,13,14}$ Finally all these platelets are parallel to the wafer surface as this orientation minimizes the formation energy of the defect. ${ }^{12}$

In summary, the growth kinetics of platelets formed during the continuous hydrogenation of a $\mathrm{Si}$ substrate/SiGe/Si heterostructure was quantitatively studied by TEM. During hydrogenation, large (001) platelets/micro-cracks are formed in the $\mathrm{Si}_{0.80} \mathrm{Ge}_{0.20}$ layer which progressively "absorb" the platelets initially distributed in the upper Si layer as well as hydrogen atoms and vacancies continuously provided at the surface. A detailed scenario has been proposed considering the Ostwald ripening of a population of precipitates in presence of a constant source (the surface submitted to hydrogenation) and a sink of increasing efficiency (the SiGe layer containing large (001) platelets). This mechanism involves the emission, diffusion and capture of vacancies and hydrogen atoms. The SiGe layer is thought to first capture the vacancies created by the plasma treatment and/or emitted by the platelets located in the upper Si layer then trap hydrogen. Finally, this type of process and associated phenomenon can be used not only to precisely localize the micro-cracks then the fracture line at a given depth but also to "clean" the top layer from pre-existing defects. We have demonstrated this possibility.

The work at LANL was supported by the Department of Energy, Office of Basic Energy Science.

${ }^{1}$ M. Bruel, Nucl. Instrum. Methods Phys. Res. B 108, 313 (1996).

${ }^{2}$ S. Personnic, F. Letertre, A. Tauzin, N. Cherkashin, A. Claverie, R. Fortunier, and H. Klocker, J. Appl. Phys. 103, 023508 (2008).

${ }^{3}$ N. M. Johnson, F. A. Ponce, R. A. Street, and R. J. Nemanich, Phys. Rev. B 35, 4166 (1987).

${ }^{4}$ A. Y. Usenko and A. G. Ulyashin, Jpn. J. Appl. Phys., Part 1 41, 5021 (2002).

${ }^{5}$ N. H. Nickel, G. B. Anderson, N. M. Johnson, and J. Walker, Phys. Rev. B 62, 8012 (2000).

${ }^{6}$ L. Shao, Y. Lin, J. G. Swadener, J. K. Lee, Q. X. Jia, Y. Q. Wang, M. Nastasi, P. E. Thompson, N. D. Theodore, P. K. Chu, T. L. Alford, J. W. Mayer, P. Chen, and S. S. Lau, Appl. Phys. Lett. 87, 091902 (2005).

${ }^{7}$ A. J. Pitera and E. A. Fitzgerald, J. Appl. Phys. 97, 104511 (2005).

${ }^{8}$ T. Lagarde, J. Pelletier, and Y. Arnal, J. Phys. IV 08, Pr7-121 (1998).

${ }^{9}$ J. Grisolia, G. Ben Assayag, and A. Claverie, Appl. Phys. Lett. 76, 852 (2000).

${ }^{10}$ X. Hebras, P. Nguyen, K. K. Bourdelle, F. Letertre, N. Cherkashin, and A. Claverie, Nucl. Instrum. Methods Phys. Res. B 262, 24 (2007).

${ }^{11}$ L. Shao, Y. Lin, J. G. Swadener, J. K. Lee, Q. X. Jia, Y. Q. Wang, and M. Nastasi, Appl. Phys. Lett. 87, 251907 (2005).

${ }^{12}$ M. Nastasi, T. Höchbauer, J. K. Lee, A. Misra, J. P. Hirth, M. Ridgway, and T. Lafford, Appl. Phys. Lett. 86, 154102 (2005).

${ }^{13}$ B. Aspar, M. Bruel, H. Moriceau, C. Maleville, T. Poumeyrol, A. M. Papon, A. Claverie, G. Benassayag, A. J. Auberton-Herve, and T. Barge, Microelectron. Eng. 36, 233 (1997).

${ }^{14}$ F. A. Reboredo, M. Ferconi, and S. T. Pantelides, Phys. Rev. Lett. 82, 4870 (1999) 